\title{
La maternidad subrogada: ¿«solidaridad» o «explotación»?
}

\section{The subrogate maternity: «solidarity» or «exploitation»?}

\author{
Roberto Germán Zurriaráin*
}

\section{Resumen}

En este artículo se exponen las objeciones éticas y jurídicas a la maternidad subrogada.

Algunos opinan que ésta es una cuestión de solidaridad con las parejas infértiles, por lo que es una práctica reproductiva, que nace de la autonomía de la mujer gestante y del derecho que a todo ser humano le asiste de ser padres.

Otros opinan que los defensores de la maternidad subrogada en cualquiera de sus dos modalidades: comercial y altruista, olvidan a los dos sujetos más importantes implicados en la misma: la mujer gestante y su bebé.

Consideran que la maternidad subrogada discrimina y cosifica al bebé y a la mujer gestante mercantilizando e instrumentalizando su cuerpo. Utiliza a la gestante y al niño, como medios al servicio del cumplimiento de los deseos de otros.

Luego parece que con la admisión de la maternidad subrogada resulta evidente que la dignidad de la mujer y la maternidad no se contemplan como algo indisponible y digno de protección. También el bebé no tiene valor en sí mismo, sino que lo tiene únicamente si es querido, recibido, deseado.

\footnotetext{
* Roberto Germán Zurriaráin. Universidad de La Rioja (España). Correo electrónico: roberto.german@unirioja.es

Recibido el 04 de septiembre de 2019. Entregado el 30 de septiembre de 2019.
} 
En definitiva, no se puede admitir una práctica reproductiva que, en mi opinión, tiene como objetivo ser padre o madre a cualquier «precio».

Palabras clave: derecho a ser padres, bebés, Ley española 14/2006 sobre Técnicas de Reproducción Humana Asistida.

La maternidad subrogada ${ }^{1}$ es una práctica cada vez más extendida a la que se le han dado también otros nombres: «gestación por sustitución», «vientres, úteros o madres de alquiler», «gestación subrogada», «maternidad por sustitución», «alquiler de útero», «maternidad de encargo», «maternidad portadora», «subrogación uterina».... ${ }^{2}$

No se puede obviar que este tema es de gran actualidad, no sólo por las recientes propuestas políticas presentadas para regular y legitimar jurídicamente esta técnica, sino también y, sobre todo, porque algunos famosos han conseguido ser padres y madres por este procedimiento reproductivo.

Los que están a favor de la maternidad subrogada, la presentan como una forma de ayudar a las parejas que no pueden tener hijos, ${ }^{3}$ dándoles la oportunidad de ser padres o madres. En concreto, argumentan que un contrato, realizado con una «madre de alquiler», se celebra entre adultos autónomos y responsables; ésta tiene libertad de elección y de ejercer el derecho a la autonomía de su voluntad, ${ }^{4}$ de tal manera que cada cual es libre de hacer con su cuerpo y su vida lo que prefiera, y en tal supuesto la ley no debiera interponerse. En efecto, los partidarios de este procedimiento reproductivo afirman que su legitimidad se basa en la autonomía de la mujer embarazada.

En definitiva, los que están a favor de la gestación de alquiler sostienen que esta práctica no perjudica a terceros y redunda, necesariamente, en beneficio de todos los sujetos implicados. ${ }^{5}$ 
Pero la realidad es bien distinta. Esta visión ingenua y parcial olvida las profundas implicaciones éticas y jurídicas que conlleva la maternidad subrogada, y omite a los sujetos más importantes implicados en la misma: la mujer gestante y su bebé.

Por eso, lo primero de todo hay que preguntarse: ¿qué es la maternidad subrogada? ${ }^{6}$ Esta supone el nacimiento de un niño que es gestado por una mujer ajena a quien desea tener el hijo, bien sea una pareja (heterosexual u homosexual), una mujer sola o un varón solo. Para ello se utiliza alguna de las alternativas que ofrece la reproducción humana asistida, pudiendo el óvulo ser aportado por la mujer que va a gestar, en cuyo caso se recurre a la inseminación artificial con el esperma del padre o donante (cuando los óvulos de la madre biológica no son óptimos, o uno solo quiere ser padre), o ser implantando un embrión producido por fecundación in vitro procedente o no de los padres que van a adoptar al niño; es decir, la madre genética podría ser la mujer que hace el contrato, la gestante o una donante ajena al contrato de la maternidad subrogada.

En resumen, una madre de alquiler es una mujer que acepta, por acuerdo (la mayoría de los casos por remuneración económica), quedar embarazada con el objetivo de engendrar y dar a luz un niño que va a ser criado por otros. Por consiguiente, en los contratos de subrogación ${ }^{7}$ la mujer alquila su cuerpo. En definitiva, en este tema, hay un contrato, unos contratantes, una mujer contratada y un «producto» (el bebé).

Pero también, la maternidad de alquiler puede realizarse de forma exclusivamente altruista, ${ }^{8}$ es decir, sin ninguna remuneración económica. Así, una mujer fértil, puede establecer un acuerdo con otra mujer infértil, comprometiéndose a llevar a término el embarazo, sin que medie una remuneración económica, lo que se denomina «subrogación gestacional altruista». Esta modalidad es la menos frecuente, pero es muy citada por aquellos interesados en promover la maternidad por sustitución. Ahora bien, la maternidad subrogada, en cualquiera de sus dos modalidades, conlleva, desde el punto de vista ético y jurídico, muchas objeciones: 


\section{La mujer no es tratada como una persona, sino como un objeto}

La maternidad subrogada supone la utilización de la mujer como una máquina de reproducción y se regula a través de un contrato, en el que también se ve al hijo, que está en el vientre de esa mujer, como un objeto meramente comercial. Pero un hijo y una mujer nunca pueden ser un producto o una cosa, como si fuesen objetos de una cesión.

Por tanto, uno de los problemas de toda maternidad subrogada es que supone la instrumentalización y la despersonalización del cuerpo de la madre gestante, ignorando la distinción básica entre personas y cosas. Las personas, evidentemente incluyendo su cuerpo (el vientre de la mujer), no pueden ser objeto de comercio. De este modo, la libertad de los individuos para establecer contratos en mutuo provecho tiene límites, especialmente, cuando el motivo de dicho contrato es el mismo ser humano (no hay respeto a la persona sin respeto a su dimensión corporal), por lo que el acto de «vender» u ofrecer el cuerpo entraña un grave problema social y humano.

Por todo ello, la maternidad por subrogación o gestación de alquiler es, inequívocamente, una nueva forma de explotación de la mujer, contraria a su dignidad, al usar su cuerpo, y por tanto su persona, ${ }^{9}$ como un objeto negociable, incubadora humana o un simple receptáculo de una gestación para satisfacer deseos ajenos: «La maternidad subrogada no respeta la dignidad de la madre portadora, ya que presupone una concepción dualista de la misma que la disgrega: por un lado, sitúa sus sentimientos, sus emociones, su razón y su autonomía y, por otra, su dimensión corporal. Desde esta perspectiva, el cuerpo de la mujer portadora es un "algo", un objeto disponible y susceptible de cualquier transacción y queda reducido a desempeñar un papel puramente instrumental»s. ${ }^{10}$

Por otro lado, no existe un «derecho a la procreación», un «derecho al hijo» que justifique un pretendido derecho individual a la 
maternidad subrogada. Es verdad que el deseo de las parejas estériles debe ser escuchado por la sociedad, pero no a cualquier precio. Los deseos, por muy buenos y loables que éstos sean, son deseos y no deben ser considerados como derechos, máxime si ello implica lesiones a la dignidad y a los derechos de otros sujetos implicados, especialmente de las mujeres más pobres o vulnerables y de los hijos.

Por ello, no existe un derecho «a convertirse en padre» en virtud de la voluntad de los heterosexuales, ni de los homosexuales, ni de los individuos que han decidido permanecer solteros. No existe un derecho que permita disponer de otra persona como de una mercancía. En todo caso, existe el derecho que asiste a los hijos a tener padres. Los deseos de paternidad tienen como límite la dignidad humana de la mujer gestante y la del bebé y la protección de sus derechos fundamentales.

Nuestra sociedad ha hecho suyos como pilares básicos los derechos humanos. De tal manera, que se debe proteger a los ciudadanos para que puedan ser respetadas sus actuaciones en el ámbito de estos derechos. Ahora bien, esta protección se extiende también a proteger al individuo incluso frente a sí mismo, cuando pretenda vulnerar sus propios derechos humanos, como sería no permitir que alguien se entregue voluntariamente como esclavo, o sea compensada económicamente la donación de un órgano, aunque dichas decisiones hayan sido tomadas de forma autónoma.

Dicho con otras palabras, no todo aquello que deseamos adquiere categoría de derecho. Para satisfacer el deseo reproductivo de algunas personas de ser padres o madres (que no derecho), y que no pueden conseguirlo de manera natural, existe la adopción (para facilitarla es necesario impedir que sea un mercado encubierto; para ello, que el coste no sea tan elevado, también que se aceleren lo más posible los trámites y que los plazos no se dilaten en el tiempo), con la que se evita el mercado de personas y ayuda a los niños que no tienen recursos ni familia. En definitiva, en la adopción postnatal prevalece el derecho de los niños ya nacidos a ser adoptados para conseguir una familia; es decir, prevalece el bien 
del hijo sobre el deseo de los adultos de ser padres, pues el fin de la adopción postnatal es favorecer el bien del niño, y, en cambio, el de la maternidad subrogada es producir un niño para satisfacer el deseo de unos adultos.

Además, la autonomía personal no significa aceptar como válida cualquier decisión. En este sentido, procede plantearse si la libertad de decisión de la gran mayoría de mujeres firmantes de los contratos de maternidad subrogada, que se encuentran en una situación de especial vulnerabilidad socioeconómica, no se ve viciada por dichas circunstancias vitales, lo que genera una auténtica explotación reproductiva.

Por otro lado, la maternidad subrogada supone la ruptura del vínculo afectivo de la madre generado con el hijo durante su gestación y la obligación de tener que entregarlo al darlo a luz, por lo que la madre es presionada psicológicamente a asumir desde el inicio que el bebé no es suyo y que no puede establecer ningún contacto con él. ${ }^{11}$

En definitiva, la maternidad subrogada cosifica a la mujer, al utilizar su cuerpo para una finalidad distinta de su propio bien, al tratarla como una mercancía, como algo que se puede comprar y vender, lo que es incompatible con la dignidad de las mujeres y sus propios derechos. Supone la compraventa de personas que pretende legalizarse bajo el epígrafe de «derecho a ejercer la paternidad» y «libertad a decidir sobre el propio cuerpo». En el fondo, las mujeres gestantes son utilizadas en este negocio como una mera factoría que fabrica bebés para otros. $\mathrm{Ni}$ a los que pagan ni a los intermediarios les importa la situación de la mujer ni el vínculo que como madre se genera durante los nueve meses que el bebé está en su seno.

\section{El bebé-hijo también utilizado como una mercancía}

La maternidad subrogada convierte también al hijo concebido in vitro (de los gametos de los padres comitentes, del óvulo de la ges- 
tante inseminada con los espermatozoides del marido, o de los gametos de unos donantes) en producto comercial con control de calidad, pero un bebé es un ser humano, no un objeto de consumo para ocultar necesidades de quien lo posee y que se pueda adquirir a través de una compra.

En efecto, con la maternidad subrogada el bebé se convierte en un mero producto comercial para satisfacer el deseo de unos adultos de ser padres o de un adulto de ser padre o madre, y como tal se le pueden exigir estándares de calidad y su devolución en caso de no cumplirlos. ${ }^{12}$

Si se admitiese el deseo de los padres se le estaría negando al bebé la consideración de bien absoluto en sí mismo y por sí mismo. Se le convertiría en un objeto disponible, en algo instrumentalizable, es decir, se le estaría cosificando.

Por todo ello, en la gestación de alquiler el bebé es tratado como un objeto de compraventa y en muchos contratos se establece que la madre subrogada deberá devolver el dinero si no logra dar a luz o el bebé no tiene las condiciones de salud establecidas, lo que acentúa la inseguridad que afecta tanto a la madre subrogada como al niño. Por consiguiente, la maternidad subrogada comercial supone mercantilizar la filiación, ya que ésta dependerá de la celebración de un contrato con un fuerte contenido económico.

Por otro lado, la criatura queda en una posición muy vulnerable en la maternidad subrogada, dado que su situación depende de las cláusulas establecidas en dicho contrato, lo cual no asegura, en absoluto, la protección de sus intereses y derechos. Luego, la gestación de alquiler pone de manifiesto el dislate que es considerar al bebé como un derecho que impulsa a poseerlo de cualquier manera.

Así también, la maternidad subrogada impide al niño conocer su origen biológico e identidad. ${ }^{13}$ Tal es así que pueden llegar a ser seis adultos los que reclamen la paternidad de cada bebé nacido de una «madre de alquiler»: la madre genética o biológica (donante de los óvulos), la madre gestante (el «vientre de alquiler»), la mujer que ha encargado el bebé, el padre genético (el donante de esper- 
ma), el marido o pareja de la madre gestante (que tiene la presunción de paternidad), y el varón que ha encargado el bebé.

En definitiva, el niño se convierte en un producto de mercado que se encarga, se compra y se vende. Su objetivo no es el bien ni de la mujer gestante, ni la del niño o el interés superior del menor, sino satisfacer el deseo de unos adultos de ser padres a cualquier precio.

\section{Las graves secuelas psicológicas que quedan para los hijos y las madres}

La medicina moderna ha proporcionado evidencias que demuestran el impacto determinante del periodo prenatal para el posterior desarrollo del ser humano y los vínculos que se crean entre la madre gestante y el hijo durante el embarazo. ${ }^{14}$ Vínculo que, lamentablemente, queda roto tras el nacimiento del bebé.

Este vínculo materno natural queda reflejado en la fisiología del cerebro de la madre durante el embarazo. La madre adapta su cuerpo a esta nueva situación mediante cambios en su sistema neuroendocrino, bajo la influencia de las hormonas del embarazo. ${ }^{15}$

Cabe presuponer que un embarazo considerado como un negocio y la relación con un hijo al que se renuncia de antemano y al que se considera como un producto y una fuente de ingresos, pueda afectar al correcto desarrollo psicológico del niño, más aún cuando sepa por qué ha sido concebido, gestado y nacido.

Pero la maternidad subrogada también afecta psicológicamente a la madre que ha gestado al bebé, le ha dado a luz y tiene que separarse de él. Esos lazos de la madre son biológicos, por consiguiente, ajenos a las intenciones por las cuales ese embarazo se promueva por lo que también afectan a la maternidad subrogada altruista. Además, recientemente se ha podido constatar que el genoma de la madre puede influir, modificándolo, en el genoma del hijo. ${ }^{16}$ Esto añadiría una razón más de los lazos que se dan entre ambos. Por lo que, si adicionalmente se conoce que las modifica- 
ciones genómicas del hijo pueden trasmitirse a su descendencia, el genoma de la madre subrogada seguiría estando presente, de alguna forma, en la descendencia del hijo gestado.

Luego, los lazos existentes entre madre y bebé no sólo son afectivos o psicológicos, sino también biológicos, concretamente, fisiológicos y genómicos.

\section{El negocio económico de la maternidad subrogada}

El recurso a las madres de alquiler se ha convertido en un negocio mundial que mueve millones de euros al año. En estos momentos, la maternidad subrogada, como término medio, cuesta cerca de $90.000 € .^{17}$

Cada año este negocio mueve cientos de millones de euros o dólares. De hecho, la maternidad subrogada es una actividad comercial en la que las agencias empresariales lucran a costa del sufrimiento de los padres infértiles y la vulnerabilidad de las mujeres, sobre todo aquellas que viven en situaciones desfavorecidas, desarrollándose todo un negocio de selección de mujeres y de futuros hijos.

Así es, las agencias empresariales seleccionan a la candidata como «vientre de alquiler». Ofrecen a través de Internet un catálogo de candidatas (que reúnen los requisitos necesarios) dispuestas a alquilar su vientre y con la intención de someterse a las exigencias, condiciones ${ }^{18}$ o cláusulas impuestas, que tendrán que seguir obligatoriamente durante el embarazo.

El objetivo, como el de cualquier negocio, es que la producción sea buena y que la mujer gestante cumpla su parte del contrato, para que el producto sea justamente lo que se había contratado. Para ello, dicho contrato comienza con los procesos de selección de las madres de alquiler que incluyen un sinfín de pruebas y requisitos personales para garantizar esa «calidad» de los óvulos y del vientre que llevará al futuro hijo. Por consiguiente, se está hablan- 
do del absoluto control que se ejerce sobre la madre gestante, tanto en lo físico como en lo psíquico, al determinar las condiciones que a la misma se le pueden exigir para ser una candidata apta, lo que constituye una forma de cosificación de la madre subrogada, una intromisión en su privacidad.

Así también, estas agencias empresariales disponen de programas que incluyen servicios y gastos: la compensación económica a la madre de alquiler, servicios de la inseminación artificial, servicio de planificación del embarazo en la zona de residencia de la madre de alquiler, examen médico completo, alimentación para el periodo de permanencia en el centro y servicio de intérprete para todo el periodo de duración del programa, preparación y firma del acuerdo entre los padres y la madre biológica, servicios jurídicos, declaración de la madre sustituta de la ausencia de demandas contra los padres biológicos, asistencia en la formalización y la obtención del certificado de nacimiento del niño.

Con todo, se puede concluir diciendo que la maternidad por subrogación no altruista es un negocio muy lucrativo, basado en la mercantilización del cuerpo de las mujeres. Una utilización y explotación de las mujeres más vulnerables, en beneficio de individuos o parejas o ricos. Tal es así, que muchas mujeres de países subdesarrollados o en vías de desarrollo han hecho de la maternidad subrogada una práctica de vida, pues los beneficios económicos que obtienen son muy superiores a los salarios que en esos países se perciben.

Tampoco se nos pueden pasar por alto la multitud de imprevistos o situaciones complicadas que pueden aparecer, como la posibilidad de un embarazo de alto riesgo para la salud de la madre gestante. ${ }^{19}$

\section{Inconvenientes jurídicos}

Hasta ahora, para el derecho, era incuestionable que la mujer que gesta y da a luz un niño era la verdadera y única madre. Sin embar- 
go, es un hecho que, en la maternidad subrogada o gestación de alquiler, comercial o altruista, la función materna puede quedar dividida entre varias mujeres, la madre biológica, la que lo gestó y dio a luz al niño, y la que lo criará como su única madre, con un vínculo genético o no, y en ocasiones una eventual donante de ovocitos.

Otro inconveniente jurídico proviene de que puede ser incierto el destino de los bebés nacidos por gestación subrogada, debido al incumplimiento de contrato y por el anonimato de su procedencia genética.

Desde el punto de vista jurídico, la maternidad subrogada está permitida sólo en algunos países de todo el mundo. Por ello, muchas personas que recurren a este procedimiento para tener hijos, deben hacerlo en el extranjero.

\subsection{Países donde la ley permite los dos tipos de la maternidad subrogada: la altruista y la remunerada económicamente o comercial}

En el momento actual la gestación subrogada comercial y altruista está legalizada en Georgia, Israel, Kazajistán, Ucrania, Rusia y en algunos estados de Estados Unidos.

En Rusia y Ucrania, la ley sólo permite la realización de este procedimiento bajo justificación médica de incapacidad de gestar. Por esta razón, sólo se permite el acceso a este procedimiento a parejas heterosexuales o mujeres solas que no puedan tener hijos por sí mismas, dejando de lado a los hombres solos y parejas homosexuales.

Georgia permite realizar la gestación subrogada desde la década de 1990, aunque sólo es posible para parejas heterosexuales casadas con incapacidad para gestar.

Las parejas homosexuales y los hombres solos tienen bastante restringido el acceso a la gestación subrogada; tan solo la legislación de los estados estadounidenses citados permite este procedimiento para este colectivo. 
5.2. Países en los que la gestación altruista con condiciones está permitida, pero no la comercial

Permiten la maternidad subrogada altruista, no la comercial, Holanda, Canadá, Bélgica, Portugal, Tailandia, India, Grecia, México, Reino Unido, Israel, Luxemburgo, Dinamarca, Nueva Zelanda y algunos estados de Estados Unidos.

Portugal, por ejemplo, legalizó la subrogación altruista, sólo a matrimonios o parejas de hecho, heterosexuales, cuyas mujeres carezcan de útero o que por alguna razón médica no tuvieran posibilidad de gestación.

En Tailandia estaba legalizada todo tipo de maternidad subrogada, pero en agosto de 2015 entró en vigor una ley prohibiendo la comercial, admitiéndola solamente en el caso de que la madre gestante fuese hermana de uno de los padres contratantes. En el caso de que los componentes de la pareja fuesen hijos únicos o no tengan hermanas, se permite recurrir a una madre subrogada ajena a la familia. Además, la ley de aquel país permite las madres de alquiler solamente para parejas heterosexuales nacionalizadas (las parejas compuestas por una tailandés/a y un extranjero/a deberán esperar tres años a partir de la boda para ser candidatos a la maternidad subrogada). La ley prohíbe la maternidad subrogada a parejas no casadas y homosexuales.

En la India, se legalizó la maternidad subrogada comercial en 2002, pero su gobierno anunció en septiembre de 2016 su propósito de prohibir la maternidad subrogada con fines comerciales, a la que desde ese momento sólo podrán recurrir de forma altruista las parejas heterosexuales indias legalmente casadas al menos durante cinco años, que justifiquen medicamente su infertilidad y que exista un vínculo de parentesco entre la gestante y los comitentes. No pudiendo acceder a la maternidad subrogada, por tanto, las parejas extranjeras, las parejas homosexuales y los solteros, tampoco las parejas que tengan ya algún hijo biológico o adoptado. 
En Grecia, desde julio de 2014, se permite la gestación por subrogación sólo en su modalidad altruista a griegos y ciudadanos comunitarios, si son matrimonios heterosexuales o personas solteras. La mujer no debe de tener más de 50 años; aunque la madre gestante puede recibir una compensación económica por las molestias que pueda tener, gratificación que no debe exceder de los 10.000 euros.

En México, la nueva ley de 2016 prohíbe la gestación subrogada para cualquiera que sea extranjero o que no cumpla los estrictos requisitos establecidos; es decir, sólo pueden acceder a la maternidad subrogada los ciudadanos mexicanos. Concretamente, en el estado de Tabasco sólo se permite la gestación subrogada altruista a parejas heterosexuales mexicanas incapaces de gestar, la madre comitente tiene que ser menor de 40 años; en cambio, la gestante debe tener entre 25 y 30 años, contar con seguro médico, y aprobación de la Secretaría de Salud. En el estado de Sinaloa la ley sólo permite la maternidad subrogada a parejas heterosexuales mexicanas siempre que exista una incapacidad médica. En cambio, en el estado de Coahuila la gestación de alquiler está prohibida. En el estado de Querétaro, al igual que en el caso anterior, no está permitida.

Por consiguiente, en estos momentos, la gestación subrogada en México no está disponible para extranjeros.

\subsection{Países en los que la maternidad subrogada está expresamente probibida}

Alemania, Francia, España, Italia, Suiza, Austria, Noruega, Suecia, Islandia, Andorra, Bulgaria, Finlandia, Malta, Montenegro, Serbia, Eslovenia, Turquía, Estonia y Moldavia prohíben cualquier modalidad, comercial o altruista, de maternidad subrogada.

Otros países que por ley tienen prohibida la gestación subrogada son Arabia Saudita, Pakistán, China y Japón. Lo mismo sucede con algunos estados de Estados Unidos.

En esta dirección, el Parlamento Europeo, en el 2011, adoptó una resolución en contra de la legalización de la maternidad subro- 
gada, «por constituir una explotación del cuerpo de la mujer y los órganos reproductivos», basándose para ello en la Convención de los Derechos del Niño, que en su art. 7.1, estipula que «cada niño tiene el derecho de conocer y ser cuidado por sus padres».

Más recientemente, el pleno del Parlamento Europeo, de 30 de noviembre de 2015, en su Informe Anual sobre los Derechos Humanos y la Democracia en el Mundo 2014 y la política de la Unión Europea en la materia, declara: «Condenamos la práctica de la maternidad de alquiler, ya que atenta contra la dignidad humana de la mujer, de su cuerpo y de sus funciones reproductivas, puesto que se la utiliza como una mercancía, por ello, manifiesta que la práctica de la subrogación gestacional, que implica la explotación de la reproducción y el uso del cuerpo humano con fines de lucro o de otro tipo, especialmente en el caso de mujeres vulnerables de los países en desarrollo, debe ser prohibida y tratada como una cuestión de urgencia en los documentos sobre los derechos humanos». ${ }^{20}$

Por su parte, el Tribunal Europeo de Derechos Humanos, en la Sentencia del 24 de enero de 2017, reconoce que la maternidad subrogada atenta contra los derechos humanos. ${ }^{21}$

Por otro lado, el Comité de Asuntos Sociales, Saludy Desarrollo Sostenible de la Asamblea Parlamentaria del Consejo de Europa, reunido en París, el 23 de noviembre de 2016, debatió el problema de los «Derechos Humanos y Aspectos Éticos relacionados con la Subrogación», para la posible aprobación de esta práctica. Rechazaba la maternidad subrogada al «considerar que valoraba a las mujeres y a los niños como mercancías que se pueden explotar».

Ahora bien, como se ha dicho, en la mayoría de estos países consideran sin efecto los contratos tanto de la maternidad subrogada comercial como de la altruista, pero existe en muchos de esos países, la posibilidad, como en España, en las que, estando prohibida por su ordenamiento jurídico, se convierte en una práctica consentida, cuando se realiza en algún país extranjero, donde se considera un contrato válido al que se puede dotar de efectos registrales en el país de procedencia de los comitentes. ${ }^{22}$ 
Así, en el caso de España, la legislación española ${ }^{23}$ no permite la gestación de alquiler; es decir, son nulos los contratos de gestación por sustitución en cualquiera de sus dos modalidades. Sí está permitido realizarlos en otro país donde este procedimiento reproductivo sea legal, siempre y cuando se respeten las leyes locales del país de origen; un español puede firmar un contrato en el extranjero para este fin y volver con su bebé a España después del parto. Los hijos nacidos por maternidad subrogada en el extranjero pueden ser registrados en el consulado español del país en donde han nacido, de acuerdo con el artículo número 8 del «Convenio Europeo para la Protección de los Derechos y Libertades Fundamentales», y posteriormente ser registrados en España, al amparo de la Instrucción número 5 de la Dirección General de los Registros y del Notariado de $2010 .^{24}$ Luego, la maternidad subrogada en España no está prohibida en sentido estricto, simplemente, no tiene ningún efecto.

Precisamente, en España la Ley 14/2006 sobre Técnicas de Reproducción Humana Asistida prohíbe los contratos de gestación por sustitución. ${ }^{25}$ Para el Código Civil español la determinación de la filiación se basa en la verdad biológica (el parto), con la posibilidad de reclamación de la paternidad por el padre biológico. ${ }^{26}$ Dicho de otro modo, aunque exista un contrato formal entre los padres comitentes que han contratado los servicios, la madre de alquiler puede reclamarla potestad. Si ésta reclama al bebé, conforme a la legislación española, el contrato se invalidaría y la madre de alquiler, que ha gestado al bebé, ejercería la maternidad.

Ante este complejo problema social y jurídico, las parejas que contratan a madres subrogadas están solicitando que se les reconozcan sus derechos de ser padres de la criatura nacida. Si esto ocurriese, la maternidad dejaría de estar vinculada al hecho físico de la mujer que gestó al niño y que lo dio a luz. Se reconocería así que el deseo de ser padre y madre es suficiente para otorgar el derecho de paternidad y abriría las puertas, no solamente a las parejas infértiles, sino también a individuos solos, parejas del mismo sexo, etc., que podrían inscribir a los niños en el Registro Civil y así lega- 
lizar su paternidad. La maternidad ya no quedaría vinculada a realidades físicas (gestación y dar a luz), sino al deseo o la intención de ser padres.

Con todo, es incoherente la situación jurídica española, porque un órgano de la Administración del Estado, como la Dirección General de los Registros y del Notariado (sigue inscribiendo las filiaciones de los niños obtenidos mediante gestación de alquiler en el extranjero a favor de los comitentes) está actuando en contra de la legalidad vigente de su propio país (desatiende lo dispuesto por la Ley de Técnicas de Reproducción Humana Asistida de 2006, las sentencias del Tribunal Supremo español del 6 de febrero de 2014, y la del Tribunal Europeo de Derechos Humanos de 2017 en esta materia). Luego, la Dirección General de los Registros y del Notariado, dependiente de Ministerio Interior español, está actuando en contra del marco legal vigente y de la interpretación que del mismo ha hecho la máxima autoridad judicial en España avalada, a su vez, por el Tribunal Europeo de Derechos Humanos.

Es, por lo menos, paradójico declarar nulos los contratos de la maternidad subrogada, como en España y en otros países, para proteger a las mujeres locales de una explotación y mercantilización, y simultáneamente permitir el empleo de la subrogación en el extranjero; es decir, reconocer el efecto más significativo del mismo: la determinación de filiación del niño.

\subsection{Países donde la maternidad subrogada no está regulada legalmente}

Argentina no dispone de ley que regule la maternidad subrogada, igual que en Brasil, Chile, Chipre, Guatemala. Irlanda no tiene una ley sobre reproducción asistida general. Por consiguiente, el contrato de subrogación no es vinculante y esto puede llevar a problemas.

En Panamá, la República Checa, Perú, Hungría, Letonia, Lituania, Malta, Mónaco, Rumanía, San Marino, Bosnia-Herzegovina y Polonia, no existe una ley nacional que permita la gestación subro- 
gada, pero tampoco que la prohíba, por lo que se realiza en algunos territorios.

En definitiva, los Tratados Internacionales, las Recomendaciones de Organismos Internacionales, la jurisprudencia del Tribunal Europeo de Derechos Humanos..., muestran preocupación ante los riesgos que plantea la legalización de la gestación por sustitución.

\section{Conclusión}

La cuestión de fondo, desde el punto de vista ético, en las objeciones sobre la maternidad subrogada no radica en que se dé, en ocasiones, una mala praxis médica, o en que haya empresas o clínicas que puedan traficar con bebés (lo que es un delito penal), sino que con la maternidad subrogada se discrimina y cosifica al bebé y a la mujer gestante mercantilizando e instrumentalizando su cuerpo.

Así es, la gestación de alquiler, en cualquiera de sus modalidades, comercial o altruista, supone una utilización de las mujeres, porque trata a la gestante y al niño como medios al servicio del cumplimiento de los deseos de los comitentes, y no como fines en sí mismos, sino como medios al servicio de la satisfacción del deseo de otros.

Con la admisión de la maternidad subrogada resulta evidente que la dignidad de la mujer y la maternidad no se contemplan como algo indisponible y digno de protección, sino que se puede utilizar a la mujer para satisfacer un deseo.

Dicho esto, se les exige a los bebés unas pautas de calidad y se les priva de derechos fundamentales, aparte de su «autocomprensión» del hijo en el futuro. En este sentido, la gestación de alquiler lleva a abortos o «devoluciones» de niños «imperfectos» o al abandono del bebé comprado al terminar la relación de pareja antes de que llegara su nacimiento. 
También el bebé, un ser humano, no es indisponible, sino que es utilizado como medio para el cumplimiento de un deseo de otro u otros. Por consiguiente, el niño no tiene valor en sí mismo, sino que lo tiene únicamente si es querido, recibido, deseado.

La manera más efectiva de disuadir a los posibles padres de acudir a la maternidad de alquiler y así reducir el negocio y la explotación que ésta supone es la prohibición a los padres no biológicos de inscribir a los niños que los han obtenido por subrogación nacional e internacional en el Registro Civil; es decir, la mujer, que ha dado a luz, sería la única madre.

Finalmente, en el tema de la maternidad subrogada hay que hacerse varias preguntas: ¿Quién se va a beneficiar realmente con esta práctica?, ¿tal vez, las agencias empresariales?, ¿quiénes salen perjudicados en la gestación de alquiler?, ¿qué ocurre con las mujeres subrogadas y con los bebés?

No se puede admitir una práctica que tiene como objetivo ser padre o madre a cualquier «precio», sin pensar en la madre biológica y en el hijo y comerciar con éste y con el cuerpo de las mujeres.

Un mundo donde prevalece por encima de todo el dinero y el deseo individual es un mundo abocado a la corrupción y a la desigualdad.

Por consiguiente, por estas razones todas las decisiones y medidas relativas a la gestación de alquiler, comercial o altruista, deberían, en mi opinión, orientarse a prohibir esta práctica.

\section{Notas bibliográficas}

\footnotetext{
${ }^{1}$ Hablar de maternidad subrogada es uno más de los varios eufemismos que se usan en bioética, porque ni es maternidad, ni lo que jurídicamente se entiende por subrogación. Sobre este asunto, ver SERRANO RUIZ-CALDERÓN, JOSÉ MIGUEL. "Manipulación del lenguaje, maternidad subrogada y altruismo», Cuadernos de Bioética. 2017; 27: pp. 219-228.

2 No todos estos términos indican exactamente lo mismo, pero tienen en común «la voluntad de retirar la condición de madre a quien ha dado a luz un bebé y atri-
} 
buirla a otra, otro u otros», BELLVER CAPELLA, VICENTE. "¿Nuevas tecnologías? Viejas explotaciones. El caso de la maternidad subrogada internacional», ScIO. Revista de Filosofía. 2015; 11: pp. 23-27.

${ }^{3}$ La principal causa de la utilización de la maternidad subrogada es la falta del útero en una mujer. Esta carencia puede ser congénita o debida a enfermedades de dicho órgano que requieren su extirpación. También cuando existen alteraciones funcionales que no lo hacen útil para la gestación.

${ }^{4}$ Cf. VAN ZYL, LIEZL, VAN NIEKERK, ANTÓN. "Interpretations, perspectives and intentions in surrogate motherhood», Journal of Medical Ethics, 26. (2000), pp. 404-409.

${ }^{5}$ Cf. MaRtín CAMACHO, J. [Publicación en línea] «Maternidad subrogada: una práctica moralmente aceptable. Análisis crítico de las argumentaciones de sus detractores». 1-18. 2009. http://www.fundacionforo.com.ar/pdfs/maternidadsubrogada.pdf.Consulta: 8/09/2018.

${ }^{6}$ «El sustantivo maternidad y el calificativo subrogada evocan, cuando uno lo oye, algo irracional. ¿Cómo es posible subrogar algo tan íntimo y personal como es la maternidad?», PASTOR GARCÍA, LUIS MIGUEL, "La maternidad, su valor y sentido como núcleo del debate bioético sobre la maternidad subrogada», Cuadernos de Bioética, 27, (2017), p. 151; JouVE DE LA BARREDA, NICOLÁs, (ed.) La maternidad subrogada. Qué es y cuáles son sus consecuencias, Sekotia, Madrid, 2018; AzNAR, JUSTO. TUDELA, JULIO, "Gestacional surrogacy. Ethical aspects», Medicina e Morale. 2018; 67: pp. 277-290; COMITÉ DE BIOÉTICA DE ESPAÑA, Informe sobre los aspectos éticos y jurídicos de la maternidad subrogada, 2017. Este Informe señala que la maternidad afecta a la dignidad y a la integridad física y moral de las madres gestantes.

${ }^{7}$ Cf. Galbraith, Mhairi, Mclachlan, Hugh V., Swales, J. Kim. «Commercial Agencies and surrogate motherhood: a transaction cost approach», Health Care Analysis, 13/81 (2005), pp. 11-31.

${ }^{8}$ Que la maternidad subrogada sea altruista no modifica las objeciones éticas que presentan cualquier modalidad de la misma. Jouve de la Barreda afirma: «Los casos de maternidad por acuerdo (casi siempre por motivos de vínculos familiares o de amistad), sin mediar un contrato, son excepcionales y no son apropiadamente «maternidad subrogada» sino de "maternidad altruista", «acuerdo de gestación altruista» debiendo ser considerados como casos de fecundación in vitro heteróloga», JOUVE DE LA BARREDA, NiCOLÁS, «Perspectivas Biomédicas de la Maternidad Subrogada», Cuadernos de Bioética. 2017; 27: pp. 153 y 155.

Algunos justifican la gestación por sustitución altruista equiparándola a la donación de órganos inter vivos. Pero, en cambio, Bellver señala 6 diferencias entre esas dos prácticas. Por eso, sostienen que «a la vista de las diferencias apuntadas, resulta difícil reconocer una verdadera analogía entre la donación inter vivos y la maternidad subrogada», BELLVER CAPELLA, VICENTE, «Tomarse en serio la maternidad subrogada altruista», Cuadernos de Bioética. 2017; 27: pp. 234-236. La subrogación altruista significa que una mujer atraviesa el mismo proceso que 
en la subrogación comercial, pero no obtiene nada a cambio. Ver EKMAN, KAISA EKIS. [Publicación on line] «All surrogacy is explotation», The Guardian, 25/02/ 2016. $h$ ttps://www.theguardian.com/commentisfree/2016/feb/25/surrogacy-sweden-ban. Consulta: 8/09/2018.

${ }^{9}$ «Quedarse embarazada, como su nombre indica, supone una implicación de toda la mujer con la persona del hijo que se desarrolla en sus entrañas... La maternidad subrogada considera el cuerpo de la mujer como una realidad instrumental para usar. Es tal el bien que está en juego, que habría de abstenerse de solicitar a una mujer realizar este tipo de maternidad o de aceptar su libre disposición a hacerlo», PASTOR GARCíA, LUIS MIGUEL, "La maternidad, su valor y sentido como núcleo del debate bioético sobre la maternidad subrogada», Cuadernos de Bioética. 2017; 27: pp. 151-152; LÓPEZ MORATALLA, NATALIA. «El cigoto de nuestra especie es cuerpo humano», Persona y bioética. 2010; 14 (2); ( MONTERO, E. «La maternidad de alquiler frente a la summa divisio iuris entre las personas y las cosas», Persona y Derecho. 2015; 72: pp. 229-230.

${ }^{10}$ APARISI, ÁngelA, "Maternidad subrogada y dignidad de la mujer», Cuadernos de Bioética, 27, (2017), p. 172; Cf. CASCIANO, ANTONIO, «La subrogación en la maternidad. Fenomenología de una interacción humana despersonalizadora», Cuadernos de Bioética. 2018; 29: pp. 39-56. Esta modalidad no varía en muchos la objeción ética.

11 «La madre uterina debe vivir su embarazo en la indiferencia, en la perspectiva del abandono, con el pensamiento de que no es su hijo. Tiene prohibida, psíquica y contractualmente, la formación de cualquier vínculo sentimental con el niño que porta en ella», APARISI, ÁNGELA, op. cit., pp. 169-170.

${ }^{12} \mathrm{En}$ el caso de que el feto presente el sexo no «adecuado» o algún tipo de discapacidad durante el embarazo o tras el nacimiento, puede que los padres contratantes no asuman la discapacidad del feto y que la responsabilidad la trasladen a la madre gestante, tratando de resolverla animándole a que aborte. De todas formas, este problema habitualmente está resuelto en el contrato de subrogación. Incluso hay agencias que garantizan por escrito la obtención de un niño sano. Luego, en la mayoría de las ocasiones, los padres contratantes son los que toman esa decisión, por lo que a la mujer gestante se le puede imponer un aborto que puede o no desear. Pero, además, ¿qué pasaría con el bebé si la pareja contratante se divorcia? Y ¿si el embarazo es gemelar o triple y todos los bebés no son aceptados por los padres contratantes? ¿No estaríamos ante un caso de abandono de niños en el caso de que el número de fetos haya excedido del deseado por los contratantes; o por el mero hecho de que el niño no resulte ser del sexo deseado o nazca con algún tipo de enfermedad?

${ }^{13}$ «La gestación subrogada es también privar al hijo del derecho que tiene a que exista una continuidad entre su origen genético y su gestación biológica, entre crianza y educación... Por eso tampoco el hijo es algo que pueda ser donado por la madre subrogada, pues supondría no sólo volver a traicionar la esencia de la maternidad, que lleva a acoger al hijo engendrado, sino a no protegerlo de terce- 
ros que sobre él no tienen ningún derecho», PASTOR GARCÍA, LUIS MIGUEL, «La maternidad, su valor y sentido como núcleo del debate bioético sobre la maternidad subrogada», Cuadernos de Bioética. 2017; 27: p. 152; GARIBO PEYRO, ANA $P A Z$, «El interés superior del menor en los supuestos de maternidad subrogada», Cuadernos de Bioética. 2017; 27: pp. 245-259.

${ }^{14}$ En el claustro materno y durante la gestación se produce un diálogo molecular entre el embrión y la madre. De este diálogo molecular que depende el desarrollo armónico del nuevo ser, Cf. LÓPEZ-MORATALLA, NATALIA «Comunicación maternofetal en el embarazo». Cuadernos de Bioética. XX(3), (2009), pp. 303-315.

15 Cf. Bruntom, Paula J. Russell, John A., "The expectant brain: adapting for motherhood», Nature Reviews Neuroscience, 9, (2008), pp. 11-25. A este respecto JOUVE DE LA BARREDA sostiene: "Las células madre del feto van a quedar dispersas por el organismo de su madre a lo largo de su vida, como un recuerdo del embarazo y un seguro para su propia salud. Esto unido a los efectos sobre el desarrollo del cerebro refuerza la afirmación de la relación psicológica imborrable que se establece entre la madre gestante y el niño», JOUVE DE LA BARREDA, NICOLÁS, "Perspectivas Biomédicas de la Maternidad Subrogada», Cuadernos de Bioética. 2017; 27: p. 159.

${ }^{16}$ Cf. Vilella, Felipe. Moreno-Moya, Juan M. Balaguer, Nuria. Grasso, Alessia. Herrero, maría. Martinez, Sebastián. Marcilla, Antonio. Simón, Carlos. "Hsa-miR-30d, secreted by the human endometrium, is taken up by the pre-implantation embryo and might modify its transcriptome», Development. 2015; 142: pp. 3210-3221.

${ }^{17}$ Las cifras oscilan entre los 120.000 euros si la subrogación se lleva a cabo en Estados Unidos, y los 40.000 si se realiza en Ucrania, Georgia, México, Tailandia, Kazajistán, India o Nepal, pasando por los 80.000 de Rusia o Grecia.

${ }_{18}$ Una de las exigencias son las normas médicas y sociales para selección de las mujeres que van a gestar al niño. Las condiciones a cumplir por las candidatas a madres gestantes subrogadas tienen relación, con su condición psicosocial; es decir, una historia clínica relacionada con la valoración psíquica de la mujer, una completa evaluación de su salud; comprobar que no padecen enfermedades de transmisión sexual, y que no utilizan drogas; a una completa exploración de laboratorio para excluir infecciones por $\mathrm{VIH}$ u otras enfermedades de transmisión sexual.

${ }^{19}$ Cf. LÓPEZ GuZmÁN, JosÉ, «Dimensión económica de la maternidad subrogada ( «habitaciones en alquiler»)», Cuadernos de Bioética. 2017; 27: pp. 199-218.

${ }^{20}$ Resolución 2015/2229 (INI), parágrafo 115.

${ }^{21}$ http://www.biodiritto.org/index.php/item/875-paradiso-campanelli-grand-chambre. Consulta: 7/09/2018. La Sentencia del caso Paradiso y Campanelli c. Italia (asunto 25358/12. Gran Sala, 24 de enero de 2017) califica a los casos de maternidad subrogada donde no existe vínculo biológico, entre los comitentes y el bebé, como tráfico de seres humanos y afirma sobre el derecho de reproducción que no existe un deber del Estado de proteger el mero «deseo» de constituir una 
familia, con independencia. Además, sostienen los jueces de que la maternidad subrogada, en todas sus modalidades, es contraria a la dignidad humana porque trata a la gestante y al niño como medios al servicio del cumplimiento de los deseos de los contratantes, y no como fines en sí mismos.

${ }^{22}$ Cf. ALBERT, MARTA, «La explotación reproductiva de mujeres y el mito de la subrogación altruista: una mirada global al fenómeno de la gestación por sustitución», Cuadernos de Bioética. 2017; 27: p. 186. Para un estudio más profundo del caso español, ver pp. 189-190.

${ }^{23}$ El Tribunal Supremo español ha declarado que los contratos de la gestación por sustitución son nulos. Concretamente, el 6 de febrero de 2014 el Tribunal Supremo enjuició la pretensión de un matrimonio formado por dos varones españoles de que se inscribiese en el Registro Civil Consular español de Los Ángeles (California) el nacimiento de dos niños gemelos por medio de maternidad subrogada. La filiación de los menores había sido determinada a su favor por sentencia de un tribunal californiano de conformidad con su Código Civil de Familia. El matrimonio pretendía que se reconociera dicha filiación en España, pero el Registro Consular español denegó la inscripción acogiéndose a la nulidad del contrato de gestación por sustitución en España.

Llegado el caso a la máxima instancia judicial española, el Tribunal Supremo, afirmó que inscribir el nacimiento de los gemelos en el Registro Civil infringía el orden público internacional español, en el que se incluyen valores tan importantes como la autonomía y la dignidad de la madre gestante y el respeto a su integridad física y moral.

Los pretendidos padres aspiraban a que se reconociera a su favor la paternidad de los menores en virtud del interés superior de éstos, que en caso contrario se verían, según su criterio, en una situación de desprotección. Sin embargo, el Tribunal Supremo afirmó que la satisfacción del interés superior de los menores no es un principio que pueda conseguirse infringiendo la ley, pues ésta protege otros bienes jurídicos fundamentales que también resultan involucrados como el del respeto a la dignidad y la integridad moral de la mujer gestante, el de evitar la explotación del estado de necesidad en que pueden encontrarse mujeres pobres, o el de impedir la mercantilización de la gestación y la filiación.

Y señaló como medidas alternativas para evitar la desprotección de los menores, la posibilidad de que reclamase la paternidad aquel miembro de la pareja que había aportado sus genes al embarazo y, para el caso de que ninguno de ellos fuese padre biológico, la opción del acogimiento familiar o la adopción.

${ }^{24}$ El Consejo de Ministros español aprobó, el 12 de diciembre de 2014, que los niños nacidos de madres de alquiler pudieran ser inscritos en el Registro Civil. Todo ello, acorde con lo dictaminado en el Tribunal Europeo de Derechos Humanos, en 2014 (en claro conflicto con lo dicho por el Tribunal Supremo español en el 2014 y el propio Tribunal Europeo de Derechos Humanos, en la Sentencia del 24 de enero de 2017), en donde se reconoce el derecho del menor a ser inscrito en el Registro Civil por los padres contratantes, porque viola el artículo 8 sobre el 
Derecho al respeto a la vida privada y familiar del Convenio para la Protección de los Derechos Humanos y las Libertades Fundamentales (CEDH).

25 «1. Será nulo de pleno derecho el contrato por el que se convenga la gestación, con o sin precio, a cargo de una mujer que renuncia a la filiación materna a favor del contratante o de un tercero. 2. La filiación de los hijos nacidos por gestación de sustitución será determinada por el parto». Art. 10.

${ }^{26}$ El padre biológico siempre puede determinar la filiación del niño a su favor, quedando la posibilidad de que su cónyuge lo adopte. 